Revue des patrimoines

$40 \mid 2019$

Lits historiques. Première anthologie des lits européens du XVe au XIXe siècle

\title{
El sueño de los reyes de España. Camas de las colecciones reales españolas
}

Pilar Benito García y Mario Mateos Martín

\section{(2) OpenEdition \\ Journals}

Edición electrónica

URL: http://journals.openedition.org/insitu/24637

DOI: 10.4000/insitu.24637

ISSN: 1630-7305

\section{Editor}

Ministère de la Culture

Referencia electrónica

Pilar Benito García et Mario Mateos Martín, «El sueño de los reyes de España. Camas de las colecciones reales españolas », In Situ [En ligne], 40 | 2019, mis en ligne le 30 septembre 2019, consulté le 10 décembre 2020. URL : http://journals.openedition.org/insitu/24637 ; DOI : https:// doi.org/10.4000/insitu.24637

Este documento fue generado automáticamente el 10 diciembre 2020.

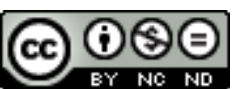

In Situ Revues des patrimoines est mis à disposition selon les termes de la licence Creative Commons Attribution - Pas d'Utilisation Commerciale - Pas de Modification 4.0 International. 


\title{
El sueño de los reyes de España. Camas de las colecciones reales españolas
}

\author{
Pilar Benito García y Mario Mateos Martín
}

Queremos agradecer la ayuda que hemos recibido de María Barrigón Montañés, Almudena Pérez de Tudela Gabaldón, Reyes Utrera Gómez, Pablo Ramos Aguado y, muy especialmente, de Juan José Junquera Mato.

1 “Trasladaron en seguida a Fernando al salón de Embajadores, donde se habían levantado siete altares portátiles, y lo depositaron en una magnífica cama imperial que había debajo del dosel sobre una tarima entapizada con terciopelo carmesí; y el mayordomo mayor hizo entrega del rey a la antigua guardia de los monteros de Espinosa para que lo custodiasen". ${ }^{1}$

2 Con estas palabras se describe el inicio de la capilla ardiente del rey Fernando VII en el Salón del Trono del Palacio Real de Madrid. Se convertía así, la cama, en un mueble de descanso tanto en vida como después de ella, dotado de un carácter público y de representación ocasional que no tenía en la cotidianeidad de la vida palatina española.

3 Como es habitual en las colecciones reales europeas, la dignidad de las camas destinadas a las testas coronadas se recalcaba por el uso del dosel, así como por la riqueza de sus materiales, tanto a nivel estructural como decorativo, elementos presentes en los ejemplos más relevantes conservados en Patrimonio Nacional.

\section{Los tiempos más pretéritos}

4 La cama más antigua de la Colección Real Española es la que se conserva en las Habitaciones de la Infanta Isabel Clara Eugenia (1566-1633). Se trata de una obra ${ }^{2}$ del siglo XVI con un sencillo armazón de cama imperial muy característico de la época, en madera de nogal con cuatro columnas lisas que sustentan la estructura superior, limitándose la decoración a las manzanillas o remates esféricos que campean en lo alto 
del dosel. La estructura queda prácticamente oculta por una rica colgadura bordada de origen oriental. Los motivos decorativos de carácter naturalista destacan sobre un fondo verde, representando el Árbol de la Vida, elemento particularmente característico de la cultura hinduista, que simboliza el Jardín del Edén y cuya imagen más difundida se plasma en los tejidos indios de algodón impresos llamados palámpores. La técnica del bordado goza sin embargo de un marcado carácter chino, ejemplo del sincretismo entre ambas culturas, por lo que es posible que fuera obra de artistas chinos asentados en India. El trabajo de bordado está realizado sobre un tejido de gasa de seda, muy apreciado en el siglo XVI dado que para su elaboración era imprescindible un telar especial que anudaba de manera minúscula los hilos de urdimbre y los hilos de trama de la tela dando como resultado un tejido muy liviano y transparente al tiempo que muy resistente y prácticamente indeformable.

5 En los primeros años del siglo XX, el conservador de la Real Armería, José María Florit y Arizcun, fue el encargado de redecorar los aposentos de Felipe II en el Monasterio de El Escorial y es entonces cuando la colgadura de gasa se utilizó para vestir la cama que habría de colocarse en el dormitorio de la hija del Rey Prudente ${ }^{3}$. El propio conservador dejó reseña escrita de su labor, digamos, decorativa y de recreación, en varios artículos, donde describió cómo encontró los elementos con los que compuso el mueble. ${ }^{4} \mathrm{En}$ el Palacio Real de Riofrío y en el propio Monasterio de El Escorial encontró el maderamen de varias camas antiguas. Por su parte, de un lote de ornamentos litúrgicos y telas almacenados en el guardamuebles del Palacio Real de Madrid, pero que también eran originarios de El Escorial, seleccionó "unas colgaduras de cama bordadas sobre gasa verde y forradas de tafetán blanco" que encajaban perfectamente en el armazón de una de las camas halladas en Riofrío al coincidir en medidas. ${ }^{5} \mathrm{~A}$ lo que no hace referencia Florit es al cielo de la cama, y de hecho -a tenor de las fotografías antiguas- no lo usó en su montaje. La pieza que se conserva en la sacristía del Monasterio, tradicionalmente se usaba como palio en las celebraciones litúrgicas, ${ }^{6}$ tiene idéntica decoración del árbol de la vida a la que se suma en la parte central del cielo, una enorme águila bicéfala que puede relacionarse con la dinastía Habsburgo a pesar de su marcado carácter oriental.

6 A lo que Florit no hace mención detallada es a la cama que montó en el dormitorio de Felipe II, pues únicamente habla en sus artículos de una colcha antigua en la estancia del rey. Por imágenes de la época, sabemos que, aunque el maderamen del lecho es el mismo, también encontrado en Riofrío, no lo es la colgadura actual compuesta con magníficos tapices de grutescos del siglo $\mathrm{XVI}^{7}$ - desgraciadamente alguno de ellos recortados- y terciopelo y que es una recreación llevada a cabo por el arquitecto Francisco Íñiguez Almech en 1956, que en aquella época era Vocal-Consejero de Bellas Artes de Patrimonio Nacional. ${ }^{8}$ La de Florit, por su parte, había sido confeccionada con cenefas de tejidos de seda con adornos renacentistas y hacía juego con la colcha. ${ }^{9}$ [Ilustración, 1] 
Ilustración 1

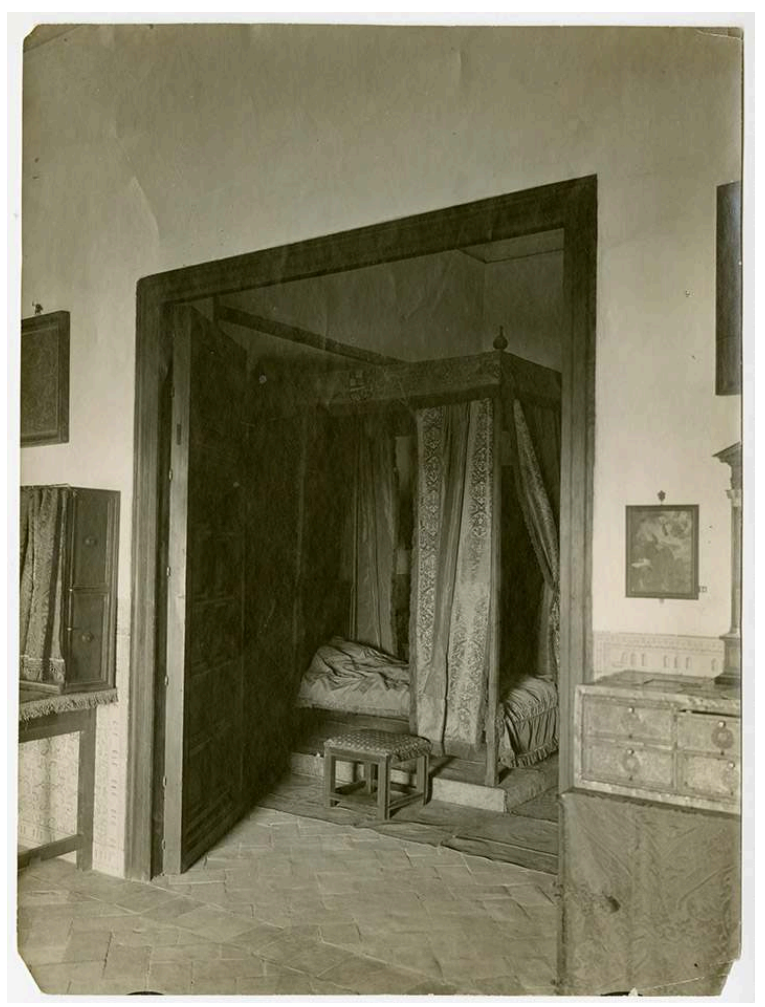

Dormitorio de Felipe I/ en el Monasterio de El Escorial. Fotografía de principios del siglo XX. Patrimonio Nacional, $n^{\circ}$ de inventario, 10124417.

(C) Patrimonio Nacional.

7 Si hablamos del S.XVII tenemos que hacer referencia a la cama de madera torneada conservada en el Palacio Real de la Granja de San Ildefonso. ${ }^{10} \mathrm{Si}$ en el caso anterior eran las colgaduras los elementos más relevantes del mueble, en esta pieza es la estructura la que adquiere el protagonismo. Su cronología ha despertado algunos interrogantes a los estudiosos. Tradicionalmente ha sido fechada en torno a 1670, al figurar varias piezas de las mismas características en el inventario realizado a la muerte de Carlos II (1661-1700). ${ }^{11}$ Sin embargo, algunos investigadores apuntan una cronología muy posterior, concretamente del siglo XIX. ${ }^{12}$ Lo más plausible, es que efectivamente se trate de un mueble del siglo XVII modificado dos siglos después. El Inventario de los cuadros, muebles y efectos existentes en el cuarto bajo del ángulo que mira a caballeriza y Plaza de Oriente ${ }^{13}$ de 1879 reseña "Una cama de palo santo de cuatro columnas salomónicas: las dos cabeceras con balaustres huecos salomónicos y remates torneados. Vestida dicha cama de cortinas, frontones exteriores e interiores de terciopelo de Genova imitación antigua adornada de fleco, alzapaños con doce borlas; el todo estilo de Enrique 20". La descripción coincide con el mueble, pero además, el inventario aporta otras informaciones al aclarar si cada mueble es antiguo o comprado, apareciendo junto al asiento del mueble que nos ocupa, "antiguo reformado" arrojando, de este modo, luz acerca de la cronología de la pieza.

De hecho, se trata de una cama de clara tipología lusa que sigue los modelos desarrollados bajo el reinado de Juan IV de Portugal (1604 -1656) y que tendrá un amplio desarrollo en determinadas zonas de la Península Ibérica. Su propiedad se atribuía tradicionalmente a la esposa del rey Fernando VI (1713-1759), la reina Bárbara 
de Braganza (1711-1758). La soberana, nacida en Lisboa, muy bien podría haber traído el mueble en su ajuar al venir a la corte española para casarse con el rey de España en 1729.

9 Este tipo de lechos, denominados en portugués de bilros y tremidos debido a sus elementos decorativos, destacan por su estructura adornada a base de arcadas y columnillas superpuestas con un rico juego de talla calada que proporciona a la pieza gran aire y vistosidad. Encontramos ejemplos similares en otras colecciones españolas, en los que, además del cabecero, la cama incluye columnas a los pies de la estructura careciendo de dosel, como es el caso de la pieza conservada en el Museo Nacional de Artes Decorativas de Madrid. ${ }^{14}$ La estructura de la cama conservada en el Palacio Real de la Granja resulta más rica y compleja, al estar dotada de cuatro pilares que sustentan el dosel, y de un piecero de gran desarrollo que repite, en menor altura, la estructura del cabecero. En ambos elementos, la decoración se realiza a base de columnillas de fuste calado helicoidal entre bolachas -y jarrones en el caso del cabecero- bajo un travesaño con talla de ondeados con remates torneados de bolas y lentejas.

\section{Los sueños del Siglo de las Luces}

10 Más abundantes en la Colección Real Española son los ejemplos pertenecientes al siglo XVIII. Uno de ellos, fechado en el primer cuarto de dicha centuria, se encuentra en el Palacio Real de Riofrío. Se trata de la cama ${ }^{15}$ utilizada por el rey Alfonso XII (1857-1885), durante su estancia en aquel palacio en 1878 cuando se retiró de la corte madrileña para vivir el duelo por la muerte su primera esposa, María de las Mercedes de Borbón (1860-1878).

11 De estructura metálica y pequeño tamaño, resulta un mueble muy fácil de transportar y de armar. Tipológicamente continúa el modelo que hemos visto hasta el momento: estructura para el colchón, columnas en los ángulos y baldaquino del mismo tamaño que la cama. Sin embargo, en este caso la estructura queda completamente oculta por la colgadura, confeccionada en damasco de seda carmesí con el característico motivo decorativo de origen genovés, conocido como damasco de la palma. Consta de guardamalletas de cielo, remates de jarrones típicamente dieciochescos en los ángulos del dosel, colcha y cortinas de abrigo, todo ello rematado con pasamanería de flequillo menudo también de seda y en el mismo color carmesí, pero combinado con blanco.

Este tipo de camas, con el dosel del mismo tamaño del lecho, fue muy habitual en los palacios españoles durante el siglo XVIII, a tenor de las reseñas del inventario de los bienes ubicados en el Palacio Real de la Granja de San Ildefonso realizado tras la muerte de Felipe $\mathrm{V},{ }^{16}$ en el que se recogen varias camas de esta tipología, todas ellas compuestas por una estructura con dosel completamente cubierto por colgaduras textiles, generalmente de damasco ${ }^{17}$.

13 Además de describir los materiales y medidas de las colgaduras de las camas, en este inventario se indica en cada caso la tipología del mueble, encontrando algunas camas "a la duquesa" -utilizando la terminología francesa- aunque en ocasiones, menciona que este tipo piezas tienen pilares en los extremos, como por ejemplo en el caso de una rica cama bordada:18 "Yt se inventarió y vió una cama a la duquesa de damasco blanco, bordado en francia, de ramos y animales [...] matizados todos en lo mas de oro y un poco de plata, mezclado con sedas [...] de todos los colores [...] Yt seinventariaron y vieron quatro pilares o buenas gracias para ellos vordados del modo que queda 
significado..." El protagonismo de la colgadura de seda es absoluto, quedando la estructura cubierta por un total de 27 piezas textiles diferentes que vestían "caveceras", cortinas, "zenefas" para el imperial, paños para la sobre cama y "almoadas".

En este mismo siglo, concretamente en 1788 , se utilizó por primera vez la fastuosa cama mortuoria de los reyes de España, conservada en el Palacio Real de Madrid y que ha sido mencionada al principio de este artículo. Fue con motivo del fallecimiento de Carlos III el 14 de diciembre de aquel año. La pieza figura descrita en los inventarios formando conjunto con un igualmente fastuoso dosel. Posiblemente la ceremonia de mayor etiqueta de cuantas se celebraban en la corte española era la de la capilla ardiente de los monarcas que se desarrolló, primero en el antiguo Alcázar de Madrid y luego en el Palacio Real Nuevo. Era una ceremonia pública, abierta a la visita y mirada de todos los súbditos de reino, siendo por tanto la única ocasión en que se podía acceder a las estancias palatinas sin tener en cuenta el origen y estatus social de aquellos que con curiosidad se acercaban a contemplar al monarca difunto. La primera vez que se especificó la función que tenía este conjunto fue en un inventario de 1795 donde se dice que estaba "destinada la dicha cama para poner de cuerpo presente a los difuntos Sres. Reyes", incluyéndose inmediatamente después el "dosel del mismo damasco y bordado a la referida colgadura de cama". ${ }^{19}$ Durante la ceremonia, la cama imperial (por lo tanto, con su propio dosel) cumplía la misma función que un sillón de trono y por ello se colocaba debajo de otro dosel independiente. [Ilustración, 2] De hecho, la instalación de la capilla ardiente, tanto en el Alcázar de los Habsburgo como en el Palacio Real Nuevo de los Borbones, se efectuaba en el Salón de Reinos o de Embajadores, que era como se denominaba indistintamente al Salón del Trono y seguía siempre idénticas pautas entre las que se encontraba el situar una cama imperial bajo un dosel. ${ }^{20}$ Las colgaduras de estos dos muebles, ${ }^{21}$ verdaderamente espléndidas, están bordadas en plata y sedas policromas sobre un damasco genovés amarillo brillante del modelo denominado de la hoja de acanto, completándose su adorno con pasamanería riquísima de rapacejo de gran largura, igualmente de plata. El trabajo, indudablemente italiano, hace del conjunto uno de los ejemplos más meritorios del bordado europeo de la época. 


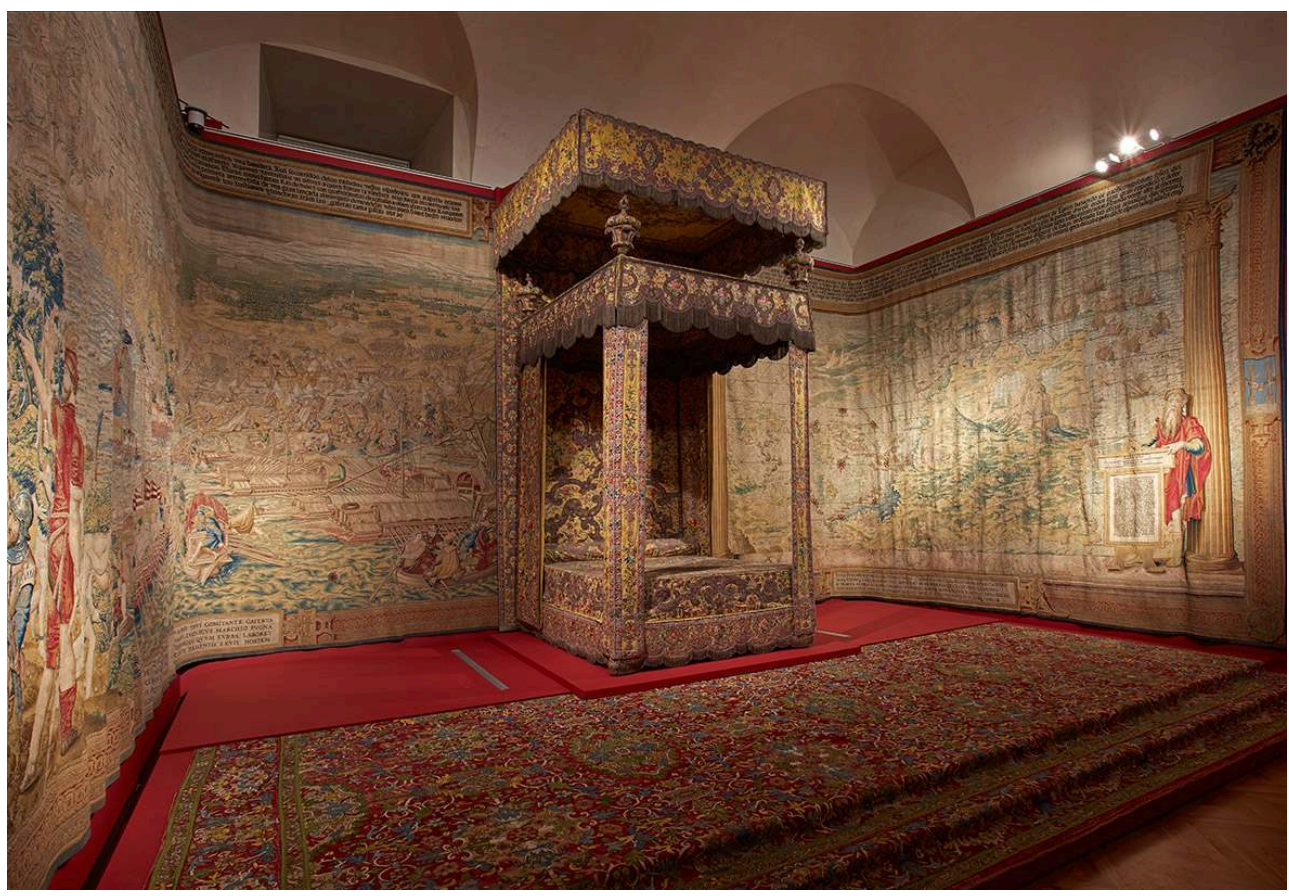

Reconstrucción de la Capilla Ardiente de Carlos III en el Palacio Real de Madrid.

(c) Patrimonio Nacional.

\section{El neoclasicismo o elsueño de larazón}

15 Finalizando el Siglo de las Luces y adentrándonos en los albores del siglo XIX, no podemos pasar por alto las dos camas pertenecientes al reinado de Carlos IV, conservadas en el Palacio Real de Madrid. Ampliamente estudiadas, primero por Juan José Junquera $\mathrm{Mato}^{22}$ y posteriormente por Pilar Nieva Soto ${ }^{23}$ y Ángel López Castán ${ }^{24}$, suponen perfectos ejemplos de lo que fue el mobiliario palatino de estilo neoclásico. Ambas que fueron realizadas para la denominada Jornada de Barcelona de 1802, ${ }^{25}$ fueron diseñadas por Antonio Pomareda ${ }^{26}$ y estaban destinadas a los príncipes de Asturias $^{27}$ y a la reina María Luisa ${ }^{28}$ respectivamente.

Muestran ambas piezas características similares: cama de dosel con estructura a base de zócalo, pilares, cabecero e imperial, todo de madera pintada en blanco y decorada con relieves dorados y medallones de vidrio eglomizado. Sin embargo, existen notables diferencias entre las dos piezas: así, la cama de los príncipes se conforma por medio de una estructura imperial sencilla, mientras que en el caso de la cama de la reina María Luisa, su imperial es de menor tamaño que el colchón, aunque notablemente más alto que el de su compañera, y está sustentado por cuadro palomillas curvas de hierro que parten de los pilares. Igualmente, existen variaciones a nivel decorativo, contando la segunda cama con un número de medallones de vidrio eglomizado notablemente superior al de la primera. Se completan ambas con sus respectivas colgaduras en raso bordado en plata y sedas de colores, la primera en azul y la segunda en un amarillo pajizo.

17 Estas dos piezas, debido a la riqueza de su factura, fueron utilizadas durante el siglo XIX como se aprecia en diversas fotografías conservadas en los fondos de Patrimonio 
Nacional. Así, la cama de los príncipes sirvió como lecho de descanso a la infanta Isabel de Borbón y Borbón (1851-1831), "la Chata" ${ }^{29}$, mientras que la cama de la reina María Luisa fue utilizada por el rey Francisco de Asís (1822-1902), como se observa en las imágenes de su dormitorio ${ }^{30}$, ubicado en los antiguos despachos de Carlos III en el Palacio Real de Madrid. A modo de curiosidad, podemos decir que desde 1902, año en que la Infanta Isabel se trasladó a vivir a un palacete propio en la madrileña calle de Quintana, sus habitaciones en el Palacio Real fueron utilizadas para recibir visitas de altos dignatarios, como la efectuada a primeros de octubre de 1913 del ilustre político, Raymond Poincaré, que en aquel entonces era presidente de la República Francesa. Con este motivo, en la prensa española, salieron imágenes de las antiguas habitaciones de la Chata, acomodadas para recibir al séquito francés, entre las que destaca la cama diseñada por Pomareda. ${ }^{31}$ [Ilustración, 3]

Ilustración 3

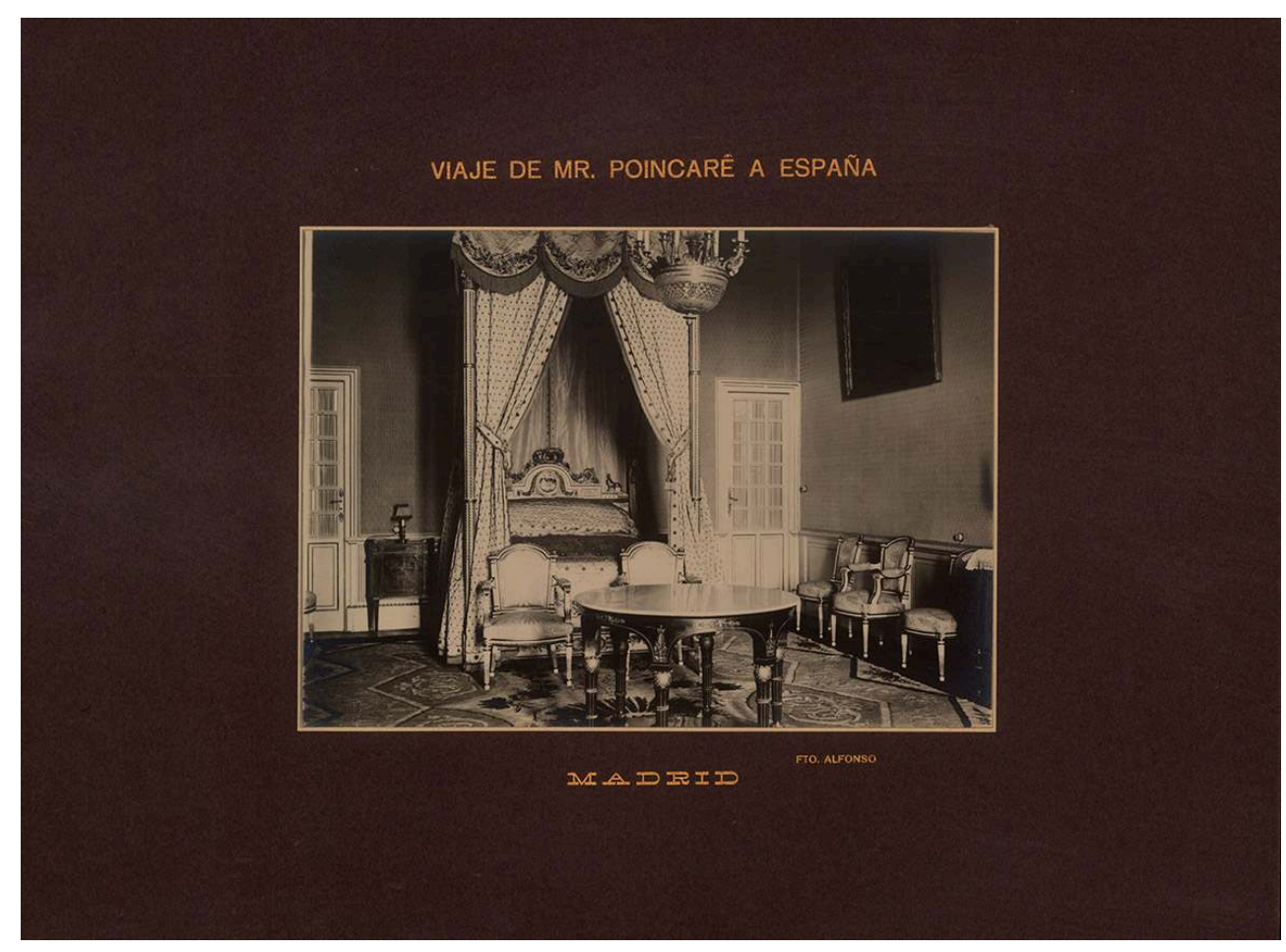

Dormitorio de Raymond Poincaré en el Palacio Real de Madrid. 1913. Patrimonio Nacional, $n^{\circ}$ de inventario 10192147.

(c) Patrimonio Nacional.

La vuelta al gusto por la antigüedad clásica que tuvo lugar durante el reinado de Carlos IV dejó, además de las dos últimas camas citadas, otros ejemplos de gran riqueza decorativa, siendo el más curioso el modelo de cama conservado en el Palacio Real de Aranjuez. ${ }^{32}$ Su diseño ha sido tradicionalmente atribuido a Jean-Démosthène Dugourc (1749-1825) y su factura los ebanistas franceses Georges II y François - Honoré Jacob, cuyos trabajos conjuntos se realizaron bajo la firma JACOB FRERES / RUE MESLEE. ${ }^{33} \mathrm{~A}$ pesar de ser una simple maqueta, se trata de uno de los ejemplos de cama más ricos y con mayor nivel de detalle decorativo de todos los conservados en Patrimonio Nacional. Se trata una cama en bateau, tipo góndola, en caoba, ébano y con aplicaciones de bronce dorado, con patas de esfinge que descansan sobre un pedestal de dos cuerpos; el cabecero y piecero se unen al resto del mueble por unos originales perros alados en 
cuyos collares se puede leer las palabras "Fidélida" y "Conjugal". Se completa su decoración con tarjas rectangulares de cristal eglomizado con escenas relativas al sueño y el descanso, componiendo así un perfecto ejemplo del gusto etrusco tan espléndidamente desarrollado por Dugourc. El pequeño modelo conserva aún parte de las colgaduras originales, en los largueros, realizadas en terciopelo azul bordado en hilo de plata con de palmetas y roleos. ${ }^{34}$

\section{El siglo XIX. La ensoñación del pasado}

19 Avanzado el S.XIX encontramos uno de los conjuntos más suntuosos del mobiliario isabelino de Patrimonio Nacional: se trata del dormitorio utilizado por la reina Isabel II (1830-1904) en el Palacio Real de Madrid, pero hoy instalado en el Palacio Real de Aranjuez, y en el que destacaba sobre todas las piezas la fastuosa cama. Todo el conjunto $^{35}$ es de un estilo neorrococó, ampuloso y pesado, siguiendo la moda del Segundo Imperio Francés. La factura de los muebles, ejecutados en bronce y maderas finas antes de 1855, ha sido tradicionalmente atribuida a talleres catalanes, si bien hace años se descubrió en la consola la estampilla del ebanista francés Hippolyte-Edme Pretot (1812-1859). ${ }^{36}$

Interesa resaltar aquí la cama, ${ }^{37}$ en la que destaca su cabecero, flanqueado por dos columnas con sendos putti a modo de cariátides y con remate mixtilíneo sobre el que campea un jarrón cuajado de flores entre dos querubines recostados. El piecero, de menor desarrollo, reposa igualmente entre dos columnas rematadas por jarrones con flores; se decora esta parte en su zona inferior, al igual que los largueros, con doradas rocallas y molduras. Todo el mueble exhibe una riquísima decoración de marquetería recreando el más puro estilo Luis XV: sobre un fondo geométrico, principalmente de rombos, marañas de flores delimitadas por tornapuntas cubren cada centímetro de la superficie. Más llamativo es el adorno en aquellas partes en las que los elementos vegetales se muestran sobre fondo negro, siendo el empleo de la madera oscura una de las notas más características del mobiliario ecléctico tan propio del S.XIX.

21 Haciendo juego con esta pieza destaca el original dosel exento ${ }^{38}$ que sobresale anclado en el muro como si de la proa de un barco se tratase. De perfil mixtilíneo, incluye medallones pintados con flores en los ángulos, similares tarjas de marquetería a las de la cama y dos volutas formando un frontón partido, sobre las que descansan sendos querubines dorados y un jarrón de marquetería.

Existen datos que describen esta cama en el Palacio Real de Madrid a finales del S.XIX: hablamos del inventario del Real Sitio realizado en $1874^{39}$ donde se cita este mueble en la "Pieza Número 36. Llamada alcoba de la ex - Reyna: vestida de raso de seda azul con ramages blancos y agremanes" bajo la siguiente descripción: "Una gran cama igual a los muebles de esta pieza, tiene un dosel del mismo genero guarnecido con pabellones de tela igual á la colgadura y raso blanco con cordonaduras y cortinas forradas de seda blanca, con sus clavos romanos y alzapaños correspondientes, y dos llamadores de campanillas de la clase; tiene esta cama á los pies un niño con una antorcha en cada columna; y en las columnas cabeceras un jarrón de flores en cada una, y en el centro otros dos niños en ademan de echar flores, y entre estos un gran jarrón de flores, todo sobre una tarima forrada de alfombra azul con greca blanca". Se aprecia una diferencia entre la cama actual y la descrita en el inventario: se trata de los dos niños con antorchas presentes en las columnas del piecero donde hoy hay jarrones; esto se debe a 
una modificación sufrida en el mueble después del primer cuarto del S.XX, fecha de la que data una fotografía $a^{40}$ en la que se observa el mueble tal y como aparece descrito en el documento de 1874.

En el Palacio Real de Riofrío se conserva la cama ${ }^{41}$ utilizada por el marido de Isabel II, Francisco de Asís (1822-1902), durante su estancia en aquel Real Sitio. De gran sencillez, se trata de una cama de campaña con estructura de acero y dosel a la polonesa. Cabecero y piecero son de barras rematadas en volutas, siendo la única diferencia entre ambos la presencia en el cabecero de las iniciales F A M B en bronce dorado. ${ }^{42} \mathrm{La}$ colgadura es de damasco de la palma y pasamanería de galón y borlones de seda, todo en color carmesí. Tipológicamente es una obra de finales del siglo XVIII, pero presenta una incógnita respecto al monograma del cabecero, pues, aunque tradicionalmente se han asociado al marido de Isabel II, las iniciales que habitualmente figuran en los objetos artísticos propiedad del rey consorte se reducían a $\mathrm{F} \mathrm{A} \mathrm{B,} \mathrm{a} \mathrm{pesar} \mathrm{de} \mathrm{que} \mathrm{su} \mathrm{nombre}$ completo era Francisco de Asís María Fernando de Borbón. La colocación de esta cama en el dormitorio de Riofrío es cuanto menos curiosa, al estar arrinconada en una de las esquinas de la habitación. La climatología invernal no afectaba demasiado al monarca que el 12 de enero de 1852, escribió a su esposa en los siguientes términos: "El tiempo aquí no es frío, pero en cambio el viento parece que va a llevarse este inmenso palacio. Ahora mismo todas las puertas y ventanas crujen como si fuera un buque en alta mar: las velas se corren, y las cortinas de damasco, sin duda para recordarnos el tiempo en que fue edificado este palacio, forman tontillo toda la noche. A mi nada me importa porque cuando me acuesto cierro todas las cortinas de mi cama y la constituyo en un nuevo edificio perfectamente acondicionado, y en el que no siento frío". ${ }^{43} \mathrm{El}$ uso de este lecho dieciochesco por el rey a mediados del siglo XIX es similar al ya descrito de la utilización de la pequeña cama que utilizó en el mismo real sitio su hijo Alfonso XII.

También dentro de ese acercamiento a épocas pretéritas, se encuentra la decoración precisamente del dormitorio Alfonso XII en el Palacio Real de Madrid. Recreando modelos franceses de camas renacentistas, se talló una cama nueva en madera de nogal que se vistió de tapices. En la confección de esta abrigada colgadura, se utilizaron cortando y dando nueva forma algunos paños de la serie tejida en la Real Fábrica de Tapices de Madrid para el dormitorio de Carlos III a mediados del siglo XVIII. Para el resto de la habitación se recortaron las altas cortinas de la alcoba del rey ilustrado, también en tapiz, ajustándolas a las puertas más bajas en la zona de las Habitaciones Privadas del mismo palacio madrileño donde don Alfonso desarrollaba su vida más íntima. ${ }^{44}$ Como se puede apreciar en la única fotografía conocida del mueble, realizada en 1884 por J. David, ${ }^{45}$ el piecero estaba concebido a modo de balaustrada con columnas torneadas. Los pilares, con base en forma de jarrón y remate en capitel jónico sustentan el dosel, coronado por una cornisa en voladizo con decoración de talla. [Ilustración, 4] 


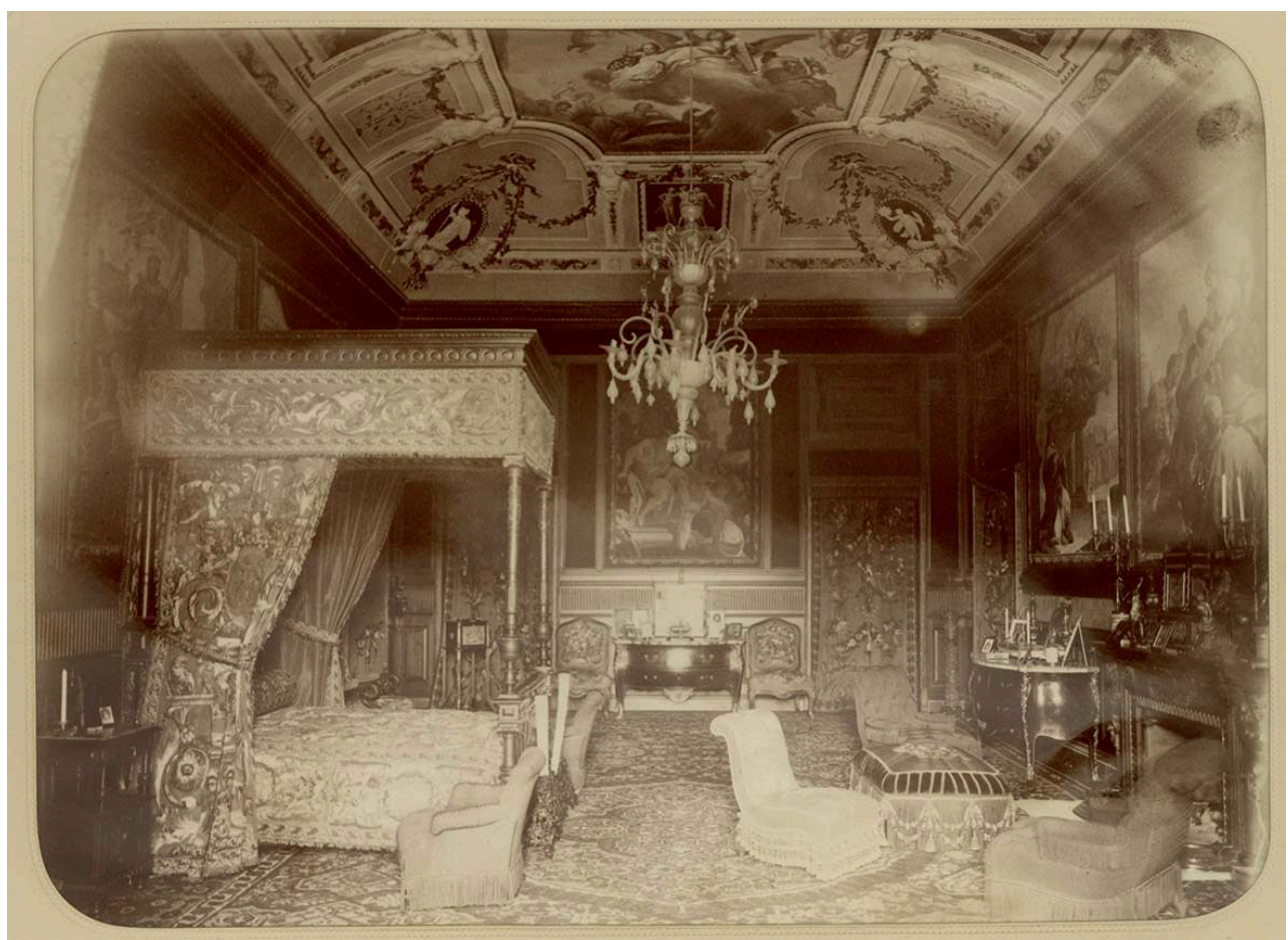

Dormitorio de Alfonso XII en el Palacio Real de Madrid. J. David, 1884. Patrimonio Nacional, $\mathrm{n}^{\circ}$ de inventario, 10183478.

(c) Patrimonio Nacional.

\section{Del Palacio de Madrid al exilio}

A medida que avanzaron los reinados, el dormitorio que había sido de Isabel II en el palacio madrileño fue ocupado por las nuevas inquilinas del Palacio Real de Madrid, siendo su última moradora la reina Victoria Eugenia de Battemberg (1887-1969), esposa de Alfonso XIII, con quien partió al exilio al día siguiente de la proclamación de la Segunda República Española el 14 de abril de 1931.

Centraba su alcoba -situada en el ala de San Gil del Palacio donde se ubicaban las Habitaciones Perivadas- una cama estilo Segundo Imperio, realizada en madera tallada, dorada y pintada de blanco. ${ }^{46}$ Columnas de orden jónico, frisos con roleos y palmetas, guirnaldas, cintas y demás elementos vegetales componen el piecero, ornado con telas bordadas de gusto antiguo a las que nos referiremos más tarde. Mayor desarrollo en altura tiene el cabecero, de estructura similar pero rematado por un ovalo bajo la corona real -tapizado con un bordado con las iniciales de Alfonso y Victoria- y flanqueado por dos sirenas que sostienen guirnaldas de flores. Parten del cabecero, dos finas pilastras de orden compuesto que sostienen la estructura del dosel, a modo de cúpula bulbosa que se decora con una corona de flores en el frontal y guirnaldas vegetales en la parte superior, en cuyo centro se alza un remate con forma de piña.

En el momento en que partieron al exilio Alfonso XIII y Victoria Eugenia, la alcoba de la reina estaba toda vestida con una delicada sedería rosa en la que hacían juego la colgadura de pared, la colgadura de cama y la tapicería de los muebles de asiento. ${ }^{47} \mathrm{Sin}$ embargo, no era la primera decoración textil que tenía la habitación. Tras los muebles 
ya mencionados del dormitorio de Isabel II, los azarosos cambios políticos con un Gobierno Provisional, el reinado de Amadeo I de Saboya (1845-1890, rey de España de 1871-1873) y la proclamación de la I República /1873-1874), con la restauración de la Monarquía, la alcoba regia cambió notablemente. Con vistas al matrimonio de Alfonso XII con su prima la infanta María de las Mercedes, fue necesario proveer de nuevo mobiliario al que sería dormitorio de la futura reina. De este modo, el diplomático Ángel Vallejo Miranda, compró en Paris "por cuenta del Rey Alfonso, una cama y mueblaje de alcoba"; se trataba de piezas que habían figurado la Exposición Universal de 1867 de la capital francesa. ${ }^{48}$ No conocemos mucho más al respecto de las colgaduras textiles de la estancia salvo que debían de ser de color azul ya que se conserva el adorno central ovalado que centraba la cabecera de la cama con la inicial de la reina bordada en oro.

Ilustración 5

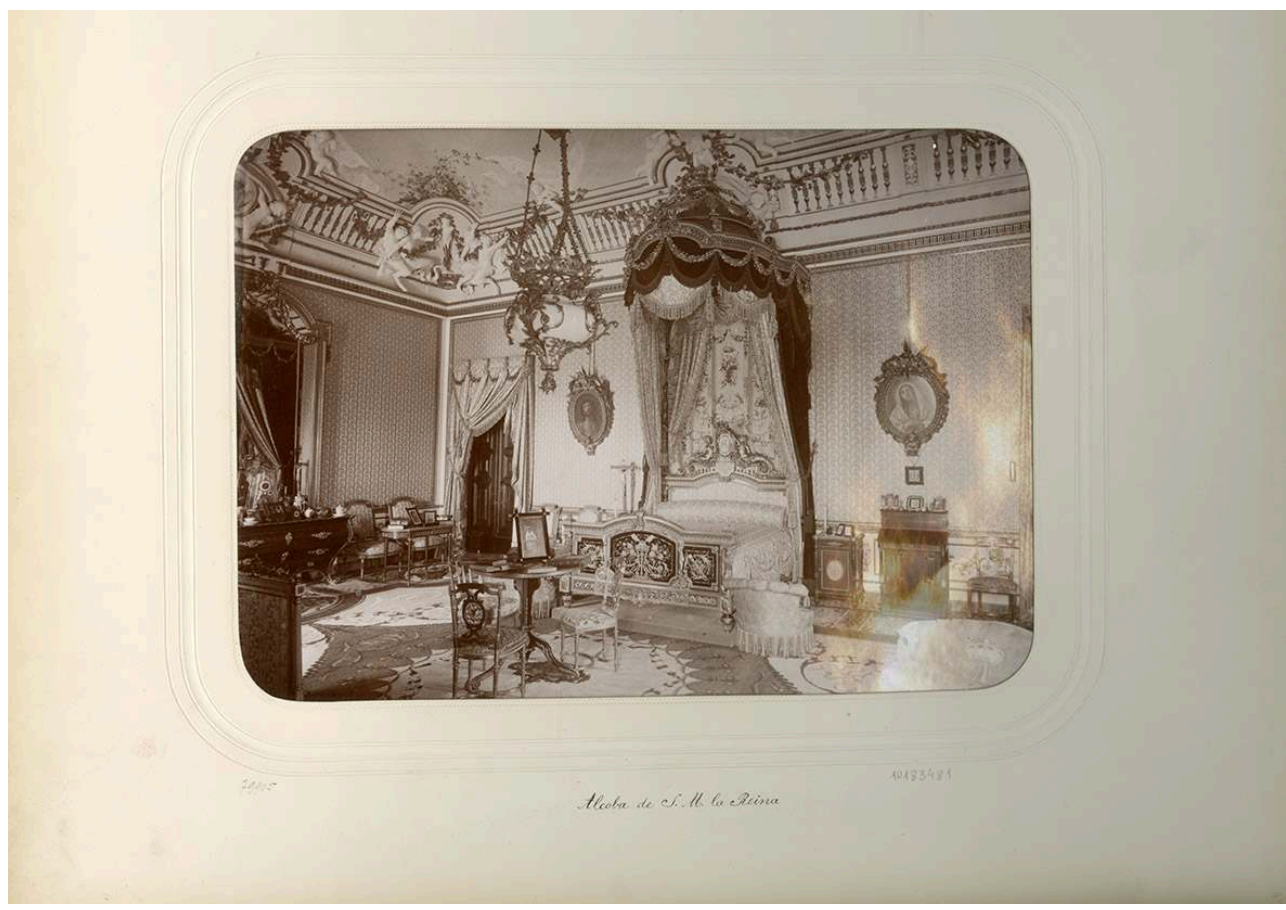

Dormitorio de María Cristina de Habsburgo Lorena en el Palacio Real de Madrid. J. David, 1884. Patrimonio Nacional, $n^{\circ}$ de inventario 10183481.

(c) Patrimonio Nacional.

Fallecida María de las Mercedes, el dormitorio pasó a ser ocupado -con los mismos muebles- por la segunda esposa de Alfonso XII, María Cristina de Habsburgo Lorena (1858-1929). De la alcoba en aquellos años se conserva una foto también realizada por J. David ${ }^{49}$ en 1884, [Ilustración, 5] que coincide en todo con la descripción de uno de los inventarios de la época en el que, además de reafirmar que el mueble había sido comprado, se dice que en la "Pieza $\mathrm{n}^{\circ}$ 36. Alcoba de S.M. la Reina" se encuentra " 1 cama talla dorada, tablero de los pies bordado en seda sobre terciopelo granate, cabecera con corona $\mathrm{Rl}$ y flores, y un medallón ovalado con la cifra bordada de la Reina Cristina; en la cabecera dos columnas de madera tallada y dorada sosteniendo una cúpula adornada de guirnaldas de madera dorada y tallada. Su pabellón de seda azul con flecos y otras cortinas de seda y terciopelo granate. En la cabecera [...] un bordado de seda color rosa que cae debajo de las otras cortinas". ${ }^{50}$ Los tres bordados sobre terciopelo granate que 
adornaban piecero aún se conservan en los almacenes del antiguo Oficio de la Tapicería del Palacio real de Madrid. ${ }^{51}$ Cabe mencionar que, en origen, y como se aprecia en la fotografía de la estancia, el dosel se completaba con guirnaldas de talla dorada que caían sobre la colgadura, adornos que no han llegado hasta nuestros días. ${ }^{52}$ Los tres adornos bordados sobre terciopelo granate que se ven la fotografía -un sahumador en el centro y un carcaj y una antorcha en los laterales, todo entre roleos y flores- fueron copiados años después cuando la cama fue utilizada por la reina Victoria Eugenia, tejiéndolos en tapiz. Precisamente, en este momento, completaba el adorno textil de la cama un pequeño edredón para los pies, con un espectacular bordado que representaba a Alfonso XIII practicando la caza. La riqueza de la alcoba de la última reina que vivió en Palacio, contrastaba con el austero dormitorio del rey, en el que una simple cama metálica centraba la estancia. Como único lujo, una manta de piel de zorro que servía de abrigo. Una imagen muy diferente a la que ofrecía el dormitorio de su padre con la cama de nogal tallada y las colgaduras de tapiz de Carlos III. ${ }^{53}$

Una vez los reyes en el exilio, durante la II República, las Habitaciones Privadas de los monarcas cambiaron notablemente al ser abiertas al público. Las transformaciones más llamativas se produjeron precisamente en los dormitorios de los reyes, en un intento de obviar la imagen más íntima de la monarquía..$^{54}$ La alcoba de Victoria Eugenia, se transformó en un salón que conservaba el mobiliario de asiento, pero en el que la cama había sido sustituida por un magnífico lienzo de Giambattista Tiepolo, San Pedro de Alcántara, pasando de esta forma a ser una estancia más, sin ningún tipo de connotación ni histórica ni política. Por su parte la alcoba de Alfonso XIII sí que perdió todos sus elementos decorativos para ser transformada en una sala de exhibición de tapices. $Y$ es que hay veces que a la Historia se le obliga a dejar paso a otras pequeñas historias y las camas en que los reyes soñaron, pasan a formar parte de nuestro imaginario de historiadores. ${ }^{55}$

\section{NOTAS}

1. - KOSTKA VAYO, Estanislao. Historia de la vida y reinado de Fernando VII de España. Madrid, 1842, Vol.3, p. 435.

2. - № de inventario, 10014076.

3. - PÉREZ DE TUDELA GABALDÓN, Almudena, "Las intervenciones historicistas de José María Florit en los Capítulos y Palacio de los Austrias en el Real Monasterio de El Escorial", Además de: revista online de artes decorativas y diseño, no $.1,2015$, pp. 115-136.

4. - FLORIT ARUZCUN, José María, "Los aposentos de Felipe II en San Lorenzo de El Escorial”, Boletín de la Sociedad Española de Excursiones, vol. 28, 1920, 1er trimestre, pp. 39-48; vol. 28, 1920, 2º

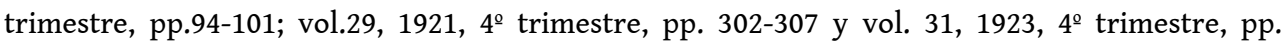
296-300.

5. - Íbidem, vol, 28, 1920, 2o trimestre, pp. 95-96.

6. - № de inventario, 10049885. Esta pieza está seleccionada para su exhibición el futuro Museo de las Colecciones Reales. 
7. - Los cartones de estos paños están atribuidos a Cornelis Floris. JUNQUERA DE VEGA, Paulina y HERRERO CARRETERO, Concha, Catálogo de Tapices del Patrimonio Nacional. Volumen I: Siglo XVI, Madrid, 1986, pp. 225-229

8. - RAMOS AGUADO, Pablo, La musealización del palacio de los Austrias del Monasterio de El Escorial. Trabajo de Fin de máster. Universidad Complutense de Madrid, 2018, pp. 29-30 y PÉREZ DE TUDELA GABALDÓN, Almudena y RAMOS AGUADO, Pablo, "Las intervenciones historicistas en el Palacio de los Austrias de El Escorial durante la primera mitad del siglo XX" en Convegno Internazionale di Studi: Musei in Euopa engli anni tra le due guerre. La conferencia de Madrid del 1934, Turín, 26-27 de febrero de 2018, (en prensa). Sobre la decoración original del palacio escurialense de Felipe II, es obligada la consulta de: PÉREZ DE TUDELA GABALDóN, Almudena, "Los muebles de la colección de Felipe II y de su hija la infanta Isabel Clara Eugenia", en El culto al objeto: de la vida cotidiana a la colección, Asociación para el estudio del mueble-Museo de Artes Decorativas de Barcelona, 27-29 de marzo de 2009, Barcelona, 2010, pp. 33-47.

9. - En todos estos trabajos, Florit había usado excepcionales tejidos renacentistas, recortando en muchas ocasionas riquísimos ornamentos litúrgicos de los creados en el Obrador de Bordados creado por Felipe II en el propio Monasterio de El Escorial. Estas vestiduras habían sido bordadas sobre las mejores sederías españolas e italianas del XVI. En las fotografías antiguas conservadas en el Archivo General de Palacio, no logra apreciarse si efectivamente son tejidos antiguos o modernos imitando antiguos. Fotografías nº de inventario, 10124417 y 10124420

10. - № de inventario, 10025897

11. - AGUILÓ, María Paz, “Cama” en MOYA VALGAÑóN, José Gabriel (comisario), Mueble español. Estrado y dormitorio. Madrid: 1990, p. 284.

12. - CASTELLANOS RUIZ, Casto. “Decoración y mobiliario en España en el S.XVIII”. En: VV. AA. Siglo XVIII: España, el sueño de la razón. Río de Janeiro: Fundación Arte Viva, 2002, p. 399.

13. - Archivo General de Palacio, Administración General, Legajo 776, Expediente 55, pieza ํo 7. La cama se encontraba entonces en el Palacio Real de Madrid.

14. - № de inventario, CE02059. AGUILÓ, María Paz, Op. Cit. (nota 9).

15. - № de inventario, 10060963.

16. - A.G.P. Administraciones Patrimoniales, San Ildefonso, Caja 22182. Copia autentica del ymbentario y tassa de los vienes pertenecientes ala testamentaria de Nro Rey y Sr Dn Phelipe V, que esta en gloria y existen en el sitio de Sn Yldephonso, con descripción y nota del Rl Palacio fuentes y otros edificios que nose tassaron, executado todo por el Sr Dn Pedro de Quintana y Azebedo del Consejo de su Magd y su Correxr en la Ciudd de Seg en virtud de la subdelegacion quesele dirigio para este fin en el año de 1747 ante Pedro Plasencia scrivano de Dho RlSitio.

17. - Como ejemplo, una de las camas descritas en el inventario se dice que constaba de hasta un total de 19 piezas textiles que forman el conjunto "de damasco carmesí [...] forrada en olandilla encarnada [...] guarnecida por las costuras con galones de oro...”. Todo ello, además, se complementaba con la las colgaduras de pared de la estancia donde se localizaba el mueble, con las que solían hacer juego: "una sobre puerta también de damasco guarnecida aimitacion de los paños ya espresados" que se completa con otras tres piezas más para el resto de vanos: Íbidem, apartado: prosigue el inventario tasa de las camas, colgaduras y cortinas de la herencia de su M. puestas al cargo de dn Juan del Moral

18. - Íbidem.

19. - AGP. Sección Reinados, Carlos IV Casa, leg.21. AGP. Sección Administrativa, legajo 769. Algo muy similar se explica en el primer inventario del oficio de Tapicería redactado tras la Guerra de la Independencia, aunque con una patriótica aclaración sobre la legitimidad dinástica, al reseñar que la cama está "destinada por nuestros legítimos Reyes para exponer sus cadáveres y los de sus hijos los Príncipes de Asturias y hacerles los funerales que tienen costumbre a cuyo fin acompaña a esta cama un dosel compañero y el fin de los funerales por lo que se inventaría a continuación". Inventario General del Oficio de Tapicería del año de 1813, asiento 꾸11. BENITO GARCíA, Pilar, 
"La muerte de Carlos III", Antologia di Belle Arti. Il Setecento, Nuova Serie, 1998, pp. 55-58 y BENITO GARCÍA, Pilar, "La muerte del Rey" y "Cama mortuoria de los Reyes de España" en BENITO GARCÍA, PILAR, JORDÁN DE URIES Y DE LA COLINA, Javier y SANCHO GASPAR, José Luis (comisarios), Carlos III. Majestad y Ornato, Madrid, 2016, pp. 337-343 y356-360.

20. - Durante los años de construcción del Palacio Real Nuevo tras el incendio del antiguo Alcázar de los Austrias, las capillas ardientes de los monarcas se instalaron en el Palacio del Buen Retiro que pasó a ser la sede temporal de la monarquía. Hasta la muerte de Carlos III, no hubo una cama imperial específica y exclusiva para este fin, pues se seleccionaba alguna de las más ricas de la colección. Sí que hubo un dosel de tapiz con las armas del emperador Carlos V. La instalación en el Antiguo Alcázar, precisamente con este dosel de tapiz, puede verse en el cuadro de Sebastián Muñoz, Las exequias de María Luisa de Orleáns, reina de España, en el Alcázar Real de Madrid conservado en la Hispanic Society de Nueva York. La última vez que se celebró esta ceremonia en el Salón de Embajadores del Palacio Real Nuevo fue a la muerte de Fernando VII. Las circunstancias políticas, el cambio de ceremonial y tal vez el olvido de la antigua etiqueta, hizo que posteriormente se realizaran en el Salón de Columnas del mismo Palacio.

21. - Números de inventario: cama, 1015670 y dosel, 10175662.

22. - JUNQUERA MATO, Juan José, La decoración y el mobiliario en los palacios de Carlos IV, Madrid, 1979, pp. 45-46, 146-148, 346-353 y docs. núms. 91 y 92.

23. - NIEVA SOTO, Pilar, "Adornos de plata y bronce en las camas de los reyes Carlos IV y Fernando VII”, Estudios de platería 2017, pp. 248-255 (243-260).

24. - LÓPEZ CASTÁN, Ángel. "Los mozos de oficio de la Real Tapicería y la creación de los muebles para la Jornada de Barcelona de 1802". En: Anuario del Departamento de Historia y Teoría del Arte. Universidad Autónoma de Madrid, 2008, vol. 20, pp. 103 - 122.

25. - Viaje de la Corte realizado a Barcelona con motivo de los dobles esponsales entre primos, los hijos de Carlos VI de España y los de su hermano Fernando IV de Nápoles: el Príncipe de Asturias, futuro Fernando VII se caso con María Antonia al tiempo que su hermana la Infanta María Isabel de Borbón hacía lo propio con el hermano de María Antonia, el futuro Francisco I de Nápoles.

26. - Antonio Pomareda era Mozo del Oficio de Tapicería. Hábil dibujante, trabajador incansable y hombre de notable buen gusto, diseñó muebles por encargo real y andado el tiempo, fue nombrado "Camero de la Real Casa".

27. - № de inventario, 10013316.

28. - № de inventario, 10090777.

29. - Fotografía $\mathrm{n}^{\circ}$ de inventario, 10159371.

30. - Fotografías no de inventario, 10216704 y 10216722.

31. - Los originales de estas imágenes se conservan en la colección de fotografía histórica de Patrimonio Nacional, $\mathrm{n}^{\circ}$ de inventario, 10192147 y 10192148 . No se sabe con exactitud.

32. - № de inventario, 10023582.

33. - JORDÁN DE URRÍES Y DE LA COLINA, Javier. En: Tesoros de los Palacios Reales de España. Una historia compartida. Méjico, 2011, p. 647.

34. - También en reinado de Carlos IV se proyectó un nuevo dormitorio para la reina María Luisa en el Palacio Real de Madrid, del que quedan pocos vestigios pues no llegó a concluirse. Se conservan los dibujos realizados por otro de los Mozos del Oficio de Tapicería, Pedro Cancio, que al igual que Pomareda era un hábil dibujante y adornista y parte de la colgadura destinada a las paredes de la alcoba. BENITO GARCíA, Pilar, "Pedro Cancio. Proyecto decorativo" en Arte de la Seda en la Valencia del siglo XVIII, Valencia, 1997, pp. 312-317; "La decoración textil de la Casa del Labrador de Aranjuez. Un jardín inacabado”, Reales Sitios, 170, 2006, pp. 57-71; “Fiebre de seda en los Palacios de Carlos IV", Carlos IV, mecenas y coleccionista, Madrid, 2009, pp.96 -116 y "L'Intrepide fabricant de Soieries Juan Antonio Miquel et l'introduction en Espagne du métier à tisser muni du mécanisme Jacquard en 1818", Raphaël Masson (coord.) Mélanges offerts à Pierre Arizzoli-Clémentel, París, 2009, pp. 52-59 y LOPEZ CASTÁN, Ángel, Op.cit, (nota 26), p. 128. 
35. - Está compuesto de cama con dosel, dos mesas de noche, un armario, un reclinatorio, un costurero, una vitrina, una consola, un sillón, seis sillas, dos entredoses, una mesa, tres espejos y seis galerías de cortina.

36. - AGUILÓ, María Paz y SANCHO GASPAR, José Luis. "El mobiliario de "mosaico vegetal" para Isabel II. El despacho de la Reina y otras piezas”. En: Archivo Español de Arte, LXXXIV, 334. Abril Junio 2011, pp. 139 - 162.

37. - № de inventario, 10028255 .

38. - № de inventario, 10028256.

39. - A.G.P. Administración General, leg. 776, exp. 64. Inventario de los muebles y efectos que existen en el ex - Palacio Real hoy de Oriente, p. 29, asiento general 6219 (particular, 13).

40. - Fotografía $n^{\circ} 10158588$.

41. - № de inventario, 10079405.

42. - Las iniciales están ancladas en una pequeña estructura de acero, sujeta al cabecero, que podría ser un añadido no original.

43. - CONTRERAS Y LÓPEZ DE AYALA, Juan de, Juan de, Marqués de Lozoya, "Cartas del rey don Francisco de Asís a Doña Isabel II", Reales Sitios, no 20, 1969, p. 27 (pp.27-36).

44. - BENITO GARCÍA, Pilar. "La decoración textil en el Palacio Real de Madrid en tiempo de Alfonso XII", Goya. Revista de arte. Números 277 - 278. Madrid, 2000, p. 280 (279-292).

45. - Fotografía $\mathrm{n}^{\mathrm{0}} 10183478$.

46. - № de inventario, 10063215.

47. - Durante los años que la reina Victoria Eugenia ocupó la alcoba, hubo al menos dos adornos textiles. El primero, desde que se casó en 1906 hasta los años 20, en que cambió las colgaduras y cortinajes de todas sus habitaciones privadas. Desconocemos la fecha exacta de esta transformación, pero los cambios han quedado reflejados en las fotografías de aquellos años y es un tema de estudio que está por acometer.

48. - BENITO GARCÍA, Pilar. "La decoración textil en el Palacio Real de Madrid en tiempo de Alfonso XII". En: Goya. Revista de arte. Números 277 - 278. Madrid, 2000, p. 282.

49. - Fotografía no 10183481.

50. - A.G.P. Administración General. Leg. 776, exp. 51. Existencias en las habitaciones por orden de los inventarios notariales. P.9, asiento 4 . El inventario carece de fecha.

51. - № de inventario 10196493.

52. - En la última restauración que se ha realizado del mueble, se ha podido comprobar que bajo la pintura blanca que cubre toda la estructura de la cama, existe una capa de color negro. Como hipótesis podemos plantear que ese color negro fuera tapado a la muerte de la reina María de las Mercedes ya que en la fotografía de 1884 , la cama parece estar entera pintada de blanco con adornos de talla dorada.

53. - Además, Alfonso XII cambió el dormitorio de habitación. En la alcoba de su padre, estableció su despacho mientras que acercaba su dormitorio al de la reina, llevándolo a una estancia más al sur dentro de la misma ala de San Gil que ocupaban las Habitaciones Privadas.

54. - Los cambios quedaron reflejados en el álbum ilustrado de LLADó, L. La riqueza artística del Palacio Nacional, Madrid 1935.

55. - Tras la Guerra Civil, se recupero en buena medida la decoración de todas las habitaciones privadas, incluidos los dormitorios de los reyes, gracias a los testimonios del antiguo personal de la Real Casa y a las fotografías antiguas que se conservaban de aquella zona de Palacio. Esta labor se debió al buen hacer (en circunstancias políticas nada sencillas) de las conservadoras Paulina Junquera de Vega y María Teresa Ruiz Alcón, a quienes dedicamos este trabajo. 


\section{RESÚMENES}

Empleada no sólo para el descanso en la vida, sino también tras la muerte, la cama tuvo en la etiqueta palatina española un componente público que hacía de ella un importante mueble de representación en determinadas ocasiones, como es el caso de los funerales de los monarcas. Su preeminencia quedaba en todos los casos marcada tanto por la presencia del dosel como por el empleo de los ricos materiales utilizados en su fabricación, destacando las ricas colgaduras que cambiaban según la moda de cada momento. Influencias chinas, hindúes, francesas o italianas están presentes en la rica colección de camas de Patrimonio Nacional, cuyos ejemplares más destacados, fechados entre los siglos XVI y XIX, se encuentran repartidos entre los diversos palacios que fueron morada de los soberanos que se sentaron en el trono español. Este conjunto de piezas supone un exquisito legado que ahora puede ser contemplado por todos aquellos que quieran soñar con los sueños de príncipes y reyes.

\section{ÍNDICE}

Palabras claves: Patrimonio Nacional, Colecciones Reales, cama, mobiliario, textiles, Palacio Real de Madrid, Palacio Real de la Granja de San Ildefonso, Palacio Real de Riofrío, Palacio Real de Aranjuez, Monasterio de San Lorenzo de El Escorial

\section{AUTORES}

\section{PILAR BENITO GARCÍA}

Jefe de Servicio de Conservación, Conservadora del Palacio Real de Madrid pilar.benito@patrimonionacional.es

\section{MARIO MATEOS MARTÍN}

Conservador de la Colección de Mobiliario, Patrimonio Nacional mario.mateos@patrimonionacional.es 